\title{
The neuropsychiatric effects of vitamin C deficiency: a systematic review
}

\author{
David Plevin ${ }^{1,2,3^{*}}$ and Cherrie Galletly, ${ }^{2,4}$
}

\begin{abstract}
Background: Vitamin C deficiency may be more common than is generally assumed, and the association between vitamin $C$ deficiency and adverse psychiatric effects has been known for centuries. This paper aims to systematically review the evidence base for the neuropsychiatric effects of vitamin $C$ deficiency.

Methods: Relevant studies were identified via systematic literature review.

Results: Nine studies of vitamin C deficiency, including subjects both with and without the associated physical manifestations of scurvy, were included in this review. Vitamin C deficiency, including scurvy, has been linked to depression and cognitive impairment. No effect on affective or non-affective psychosis was identified.

Conclusions: Disparate measurement techniques for vitamin C, and differing definitions of vitamin C deficiency were apparent, complicating comparisons between studies. However, there is evidence suggesting that vitamin C deficiency is related to adverse mood and cognitive effects. The vitamin C blood levels associated with depression and cognitive impairment are higher than those implicated in clinical manifestations of scurvy. While laboratory testing for ascorbic acid can be practically difficult, these findings nonetheless suggest that mental health clinicians should be alerted to the possibility of vitamin C deficiency in patients with depression or cognitive impairment. Vitamin $C$ replacement is inexpensive and easy to deliver, although as of yet there are no outcome studies investigating the neuropsychiatric impact of vitamin $C$ replacement in those who are deficient.
\end{abstract}

Keywords: Vitamin C deficiency, Scurvy, Neuropsychiatry, Depression, Cognition

\section{Background}

Humans, along with guinea pigs, some bats and some other primates, are among the few animals that cannot synthesise vitamin $\mathrm{C}$, which, as summarised in Fig. 1, has essential biological roles across a number of organ and tissue systems. Vitamin $\mathrm{C}$ refers to both ascorbic acid and the oxidised form of this molecule, dehydroascorbic acid, while ascorbate refers to the anion of ascorbic acid [1]. Vitamin $\mathrm{C}$ deficiency can result in scurvy, which manifests as fatigue, impaired bone growth in children, and, as a consequence of the failure of connective tissue to properly form, bleeding, including

\footnotetext{
* Correspondence: david.plevin@sa.gov.au

${ }^{1}$ Central Adelaide Local Health Network, Adelaide, SA, Australia

${ }^{2}$ Discipline of Psychiatry, The University of Adelaide, Adelaide, SA, Australia

Full list of author information is available at the end of the article
}

perifollicular haemorrhages, petechiae, ecchymoses and gingival bleeding [2].

Vitamin $\mathrm{C}$ has a significant role in modulating neurotransmitter synthesis and release in the brain. The functions of vitamin $C$ in the brain include acting as a co-factor for dopamine beta-hydroxylase in the conversion of dopamine to noradrenaline, involvement in the modulation of both dopaminergic and glutamatergic neurotransmission, and regulation of catecholamine and acetylcholine release from synaptic vesicles. Vitamin $\mathrm{C}$ also has antioxidant properties in the brain, including limiting the damage caused by ischaemia-reperfusion injury and protecting against glutamate excitotoxicity $[5,6]$.

Physiological intake and storage of vitamin $\mathrm{C}$ may be measured by both plasma and leucocyte levels. While plasma ascorbate is reflective of recent intake, it is a less

C The Author(s). 2020 Open Access This article is licensed under a Creative Commons Attribution 4.0 International License, which permits use, sharing, adaptation, distribution and reproduction in any medium or format, as long as you give appropriate credit to the original author(s) and the source, provide a link to the Creative Commons licence, and indicate if changes were made. The images or other third party material in this article are included in the article's Creative Commons licence, unless indicated otherwise in a credit line to the material. If material is not included in the article's Creative Commons licence and your intended use is not permitted by statutory regulation or exceeds the permitted use, you will need to obtain permission directly from the copyright holder. To view a copy of this licence, visit http://creativecommons.org/licenses/by/4.0/ The Creative Commons Public Domain Dedication waiver (http://creativecommons.org/publicdomain/zero/1.0/) applies to the data made available in this article, unless otherwise stated in a credit line to the data. 


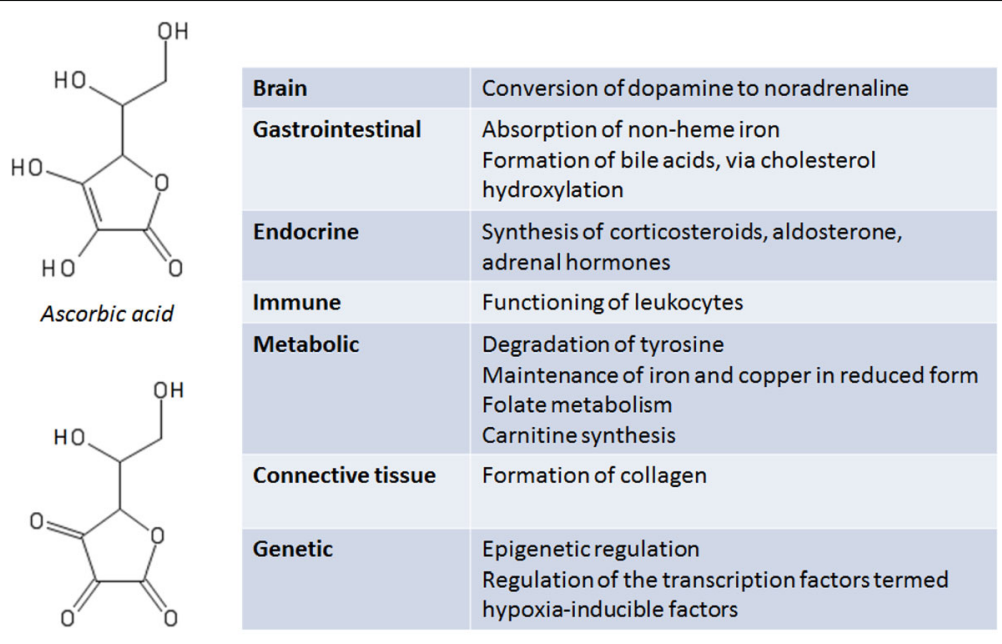

Dehydroascorbic acid

Fig. 1 Sources: [1-4]

reliable indicator of tissue and body stores than leucocyte ascorbic acid. Nonetheless, in clinical practice, measurement of plasma ascorbate is more common. Compared to measurement of ascorbic acid in leucocytes, measurement of plasma ascorbate requires a smaller volume of plasma, is less technically difficult to undertake, and is not affected by changing numbers of leucocytes [1].

A number of studies have investigated the point at which vitamin $\mathrm{C}$ deficiency manifests clinically. In five healthy prison volunteers, notable signs of clinical scurvy appeared once the whole blood levels of ascorbate had decreased to $17 \mu \mathrm{mol} / \mathrm{L}$ or below [7]. In a series of seven scurvy cases in Boston, the highest plasma ascorbic acid level among the cases was $10.2 \mu \mathrm{mol} / \mathrm{L}$ [8]. Finally, in a cohort of seven healthy young male volunteers with vitamin $\mathrm{C}$ levels depleted to between 5 and $10 \mu \mathrm{mol} / \mathrm{L}$, a daily dose of $30 \mathrm{mg}$ vitamin $\mathrm{C}$ led to a mean steady state plasma ascorbic acid of $6.9 \pm 0.5$ to $11.7 \pm 0.9 \mu \mathrm{mol} / \mathrm{L}$. After steady state was reached, a daily dose of $60 \mathrm{mg}$ vitamin $\mathrm{C}$, which was the recommended dietary allowance in the study, resulted in a steady state range of $14.9 \pm 1.0$ to $58.8 \pm$ $3.1 \mu \mathrm{mol} / \mathrm{L}$. With respect to clinical symptoms of vitamin $\mathrm{C}$ deficiency, six of the seven subjects reported fatigue and/or irritability at the nadir of the vitamin $C$ depletion. In three subjects, these symptoms resolved within 1 week of the $30 \mathrm{mg}$ daily dose, and in the other three subjects, the symptoms resolved within 1 week of the $60 \mathrm{mg}$ daily dose [9]. It is pertinent to note that the earlier studies are likely to be inaccurate in measurement of vitamin $C$, as older colorimetric assays were less specific for vitamin $\mathrm{C}$ than the high-performance liquid chromatography assay utilised by Levine and colleagues [10], and indeed the vitamin $C$ levels seen in the latter study are lower than in the earlier studies.
Most reference intervals, however, utilise a higher cutoff to classify vitamin $\mathrm{C}$ deficiency. One clinical chemistry text [1] gives the reference interval for serum vitamin $\mathrm{C}$ as 23 to $85 \mu \mathrm{mol} / \mathrm{L}$, and the definition of deficiency $\leq 11 \mu \mathrm{mol} / \mathrm{L}$. The reference interval used by SA Pathology (South Australia) is 26 to $85 \mu \mathrm{mol} / \mathrm{L}$, and the Royal College of Pathologists of Australasia [11] notes that, while the reference interval depends on the assay used, the interval is generally between 30 to $80 \mu \mathrm{mol} / \mathrm{L}$.

There is a sigmoidal relationship between oral vitamin $\mathrm{C}$ intake and plasma levels of vitamin C. Relatively small changes in vitamin $C$ intake, therefore, may lead to large changes in plasma vitamin $\mathrm{C}$ levels. In one study, oral intakes of $30 \mathrm{mg}$ vitamin $\mathrm{C}$ daily resulted in median plasma levels of less than $20 \mu \mathrm{mol} / \mathrm{L}$, but increasing the intake to $60 \mathrm{mg}$ resulted in median plasma levels of $74 \mu \mathrm{mol} / \mathrm{L}$ [12]. Another study noted that the steep portion of the sigmoidal dose-concentration curve was at daily doses between 30 and $100 \mathrm{mg}$ [9].

It is generally assumed that vitamin $\mathrm{C}$ deficiency is rare, as vitamin $\mathrm{C}$ is plentiful in fresh fruit and vegetables. However, in a population-level study in the United States $(n=7277)$, the prevalence of vitamin C deficiency in persons aged 6 years or older was $7.1 \%$ (95\% confidence limits, 5.3 to $9.2 \%)$. In this study, vitamin $C$ deficiency was defined as serum concentrations $<11.4 \mu \mathrm{mol} /$ $\mathrm{L}$; this value was chosen as it was considered to reflect the level at which scurvy may clinically manifest [13]. In a low-income population in the UK, $25.3 \%$ of men and $16.1 \%$ of women met the criteria for vitamin C deficiency (levels lower than $11 \mu \mathrm{mol} / \mathrm{L}$ ) [14]. In an Australian mental health setting - a cohort of patients attending a South Australian clozapine clinic - over 50\% of patients had vitamin $C$ levels lower than $26 \mu \mathrm{mol} / \mathrm{L}$ [15]. Vitamin C deficiency is increasingly noticed in 
other medical specialties. In a New South Wales cohort of patients attending a diabetes clinic, presenting with foot ulcers with delayed healing and/or a low-quality diet, 7 of the 11 patients tested were deficient in vitamin $\mathrm{C}$ (defined as $\leq 40 \mu \mathrm{mol} / \mathrm{L}$ ). The median vitamin $\mathrm{C}$ level in the deficient group was $15 \mu \mathrm{mol} / \mathrm{L}$. Furthermore, in the patients with foot ulcers, when vitamin $C$ supplementation was commenced, wound healing began in five of those six patients within two to 3 weeks [16].

Poor diet is common in people with psychiatric disorders [17], and so it is possible that vitamin $C$ deficiency might also be more prevalent among psychiatric populations than is generally assumed. The psychiatric effects of vitamin $\mathrm{C}$ deficiency have long been appreciated. In 1753, the Scottish physician, James Lind, wrote in his seminal treatise on scurvy that the late stage of this disease was associated with "affectio hypochondriaca, or the most confirmed melancholy and despondency of mind" [18]. Even earlier, in 1617, the English military surgeon John Woodall wrote that "a generall lazinesse" was a sign of scurvy [19].

This paper reviews the available evidence on neuropsychiatric effects of vitamin $C$ deficiency. This is important as vitamin $C$ supplements are inexpensive and readily available, if dietary interventions are not feasible or are unsuccessful.

\section{Methods}

\section{Literature search}

This systematic review was registered through PROSPERO (registration number CRD42018107781). The following databases were searched via PubMed, Elsevier and Ovid platforms, with number of English-language papers found in parentheses:

- Medline (1946 to September 2019) ( $\mathrm{n}=207)$

- Embase (1974 to September 2019) ( $\mathrm{n}=75$, unique to EMBASE)

- Cochrane Library (to September 2019) (nil relevant papers)

- PsycInfo (1806 to September 2019) $(\mathrm{n}=356)$

Only studies published in English were considered for inclusion in this review. The search was not restricted to any particular time frame; the studies included were from the inception of the databases to 4 September 2019. The search strategies for Medline, Embase and PsycInfo are described in Table 1. In Medline and Embase, the search strategy was to include all terms for vitamin $C$ deficiency, and combine, using the Boolean operator 'AND', all terms for neuropsychiatric effects. In PsycInfo, the search strategy only included all terms for vitamin $\mathrm{C}$ deficiency; given the relatively small number of hits for these, terms for neuropsychiatric effects were not specifically searched.

The titles and abstracts of all articles were reviewed by a single reviewer (DP) and independently verified by a second reviewer (CG) to identify studies that assessed the effect of vitamin $C$ deficiency on behavior, cognitive functioning and psychiatric diagnoses such as anxiety, depression and schizophrenia.

Data were extracted from papers included in the review using the standardised data extraction tool from the Joanna Briggs Institute (Appendix II in the review

Table 1 Database Search Strategy in Medline, Embase and Psyclnfo

\begin{tabular}{lll}
\hline & Vitamin C deficiency & Neuropsychiatric effects \\
\hline Title and Abstract & scurvy or ascorbic acid deficienc*or hypoascorb* or scorbutus & mental illness or mental disorder* or anxi* or obsess* or \\
Keywords (not & or vitamin c deficienc* or avitaminosis c or ascorbic acid level & compuls* or neurosis or neuroses or neurotic* or schizophren* or \\
indexed) & $\begin{array}{l}\text { or ascorbic acid concentration or vitamin c level or vitamin c } \\
\text { paranoi* or psychosis or psychoti* or cataton* or hysteric* or } \\
\text { concentration or hypovitaminosis c }\end{array}$ & $\begin{array}{l}\text { hysteria or bipolar or mania or manic or depress* or deliri* or } \\
\text { neurobehavioural or neurobehavioral or neuropsychiatr* or } \\
\text { behaviour* or behavior or irritab* or dementia* or hypochondr* } \\
\text { or hypochondria* }\end{array}$
\end{tabular}

Medline (MeSH "ascorbic acid deficiency"[mh] heading)

Embase (Emtree 'ascorbic acid deficiency'/exp heading)

Psyclnfo headings Exp Ascorbic Acid
Mental disorders [mh:noexp] or "anxiety disorders"[mh] or "Schizophrenia Spectrum and Other or Psychotic Disorders"[mh] orcatatonia [mh] or hysteria [mh] or "Bipolar and Related Disorders"[mh] or "Mood Disorders" [mh] or "Neurocognitive disorders"[mh] or "neurobehavioral manifestations"[mh:noexp] or "behavioral symptoms"[mh] or "irritable mood"[mh] or hypochondriasis [mh]

'mental disease'/de or 'anxiety disorder'/exp. or 'schizophrenia spectrum disorder'/exp. or 'catatonia'/exp. or 'hysteria'/exp. or 'disorders of higher cerebral function'/exp. or 'behavior disorder'/de or 'behavior'/exp. or 'irritability'/exp.

Given the relatively small number of hits for ascorbic acid and the associated title and abstract terms, mental illness terms were not specifically searched 
protocol published online on the PROSPERO website). The data extracted included specific details about the populations, interventions (e.g. type, intensity and duration), outcomes and study methods.

Data extraction was completed by a single reviewer (DP), with independent verification by a second reviewer (CG) to minimise bias and potential errors in data extraction. Papers selected for retrieval were assessed by two independent reviewers for methodological validity prior to inclusion in the online review using standardised critical appraisal instruments from the Joanna Briggs Institute (Appendix I in the online review protocol). Divergent opinions to inclusion were to be resolved by majority opinion with a third independent reviewer, but this was not required. The systematic review was reported as per the Preferred Reporting Items for Systematic Reviews and Meta-Analyses (PRISMA) checklist.

\section{Results}

Three small studies, conducted between 1968 and 2011, with participant numbers ranging from 4 to 7 (mean, 5.7), assessed the neuropsychiatric effects of vitamin $C$ deficiency in individuals with physical manifestations of scurvy. In six generally much larger studies, conducted between 1971 and 2019, vitamin C deficiency was assessed in individuals who did not necessarily present with physical manifestations of scurvy. Participant numbers in these studies ranged from 5 to 921 (mean, 280). The assessment of vitamin C deficiency varied markedly between studies, ranging from moderate-to-severe deficiency defined as a plasma level of $11.91 \mu \mathrm{mol} / \mathrm{L}$ or less, to "inadequate" vitamin $C$ levels being defined as a plasma level of less than $50 \mu \mathrm{mol} / \mathrm{L}$. Plasma was the blood component typically analysed in studies, but serum and whole blood were also analysed.

Overall, vitamin C deficiency has been associated with depression and cognitive impairment. The systematic review did not indicate any relationship between vitamin C deficiency and schizophrenia or bipolar disorder. Table 2 summarises the studies included in this review. In this table, all blood, serum or plasma levels of vitamin C have been standardised to SI units [20].

Assessment of bias was conducted on a qualitative basis. Given the paucity of studies available, the majority of identified studies were included in this review. The published case series all had significant methodological deficiencies, including provision of minimal information about the neuropsychiatric outcomes of interest at the time of the report or following vitamin $\mathrm{C}$ replacement. The cross-sectional studies were of higher quality, although, notably, two studies did not account for potential confounding factors when investigating the relationship between vitamin $\mathrm{C}$ deficiency and neuropsychiatric outcomes. The sole study which was neither a case series nor a cross-sectional study [21] involved experimental induction of scurvy by provision of a vitamin $\mathrm{C}$-depleted diet in a small group of male prisoners, and did not use a control group, nor were neuropsychiatric outcomes assessed prior to the commencement of the depletion of vitamin $\mathrm{C}$.

Table 2 Summary of Studies Assessing Neuropsychiatric Effects of Vitamin C Deficiency

\begin{tabular}{|c|c|c|c|c|}
\hline Study & $\begin{array}{l}\text { Number of } \\
\text { subjects }\end{array}$ & $\begin{array}{l}\text { Study definition of deficiency in } \\
\mu \mathrm{mol} / \mathrm{L} \text { and blood component } \\
\text { measured }\end{array}$ & Measurement tool & Outcome \\
\hline [21] (Kinsman et al) & 5 & $\begin{array}{l}\text { Low group, mean whole blood } \\
\text { level: } 25\end{array}$ & $\begin{array}{l}\text { Minnesota Multiphasic Personality } \\
\text { Inventory }\end{array}$ & $\begin{array}{l}\text { Increased scores in social inversion, 'neurotic } \\
\text { triad' (hypochondriasis, depression, hysteria) }\end{array}$ \\
\hline [24] (Pullar et al) & 139 & Inadequate, plasma: $<50$ & Profile of Mood States & $\begin{array}{l}\text { Increased total mood disturbance, depression, } \\
\text { confusion }\end{array}$ \\
\hline [25] (Marazzi et al) & 129 & Low, serum: $<23$ & $\begin{array}{l}\text { Inventory of Psychic and Somatic } \\
\text { Complaints-Elderly }\end{array}$ & Higher depression score \\
\hline [28] (Pearson et al) & 404 & Plasma: $<23$ & $\begin{array}{l}\text { Montreal Cognitive Assessment, } \\
\text { Warwick-Edinburgh Mental } \\
\text { Wellbeing Scale, } \\
\text { Mini-International Neuropsychiatric } \\
\text { Interview }\end{array}$ & $\begin{array}{l}\text { Higher level of cognitive impairment, no } \\
\text { association with depression or well-being }\end{array}$ \\
\hline [27] (Gale et al) & 921 & $\begin{array}{l}\text { Mild deficiency, plasma: } 11.92 \\
\text { to } 27.82 \\
\text { Moderate-to-severe deficiency, } \\
\text { plasma: } \leq 11.91\end{array}$ & Hodkinson Abbreviated Mental Test & $\begin{array}{l}\text { Statistically significant increased risk for } \\
\text { cognitive impairment for moderate-to-severe, } \\
\text { but not mild, deficiency }\end{array}$ \\
\hline [29] (Travica et al) & 80 & Deficiency, plasma: $<28$ & $\begin{array}{l}\text { Modified Mini Mental State Examination, } \\
\text { Revised Hopkins Verbal Learning Test, } \\
\text { Symbol Digits Modalities Test, Swinburne } \\
\text { University Computerized Cognitive } \\
\text { Assessment Battery }\end{array}$ & $\begin{array}{l}\text { Poorer outcome on numerous measures of } \\
\text { cognitive function }\end{array}$ \\
\hline [22] (Walker) & 7 & Clinical scurvy & $\mathrm{n} / \mathrm{a}$ & Degree of confusion noted \\
\hline [23] (Deligny et al) & 4 & Clinical scurvy & $\mathrm{n} / \mathrm{a}$ & Intense asthenia in all patients \\
\hline [26] (Mitra) & 6 & Clinical scurvy & $\mathrm{n} / \mathrm{a}$ & Severe depressive state in all patients \\
\hline
\end{tabular}




\section{Depression}

Two case series reported the presence of depression or depression-like symptoms in patients with scurvy. A severe depressive state was described in all members of a 1968 cohort of seven dermatology patients with chronic scurvy. The depression resolved within a few days of ascorbic acid replacement therapy [22]. Four patients in Martinique with scurvy (aged 34 to 77 years; 1 female, 3 male), reported in 2011, all had "intense asthenia", and one patient had depression. All patients in this cohort had an ascorbic acid level below $3 \mu \mathrm{mol} / \mathrm{L}$ [23].

In 1971, an experimental cohort of five healthy prisoners, aged 26 to 52 years, with experimentally-induced ascorbic acid deficiency, was divided into groups according to the level of ascorbic acid. It was reported that, for individual patients, vitamin $\mathrm{C}$ depletion led to statistically significant higher scores on measures of social inversion and the so-called "neurotic triad" (hypochondriasis, depression and hysteria) on the Minnesota Multiphasic Personality Inventory, and that repletion of vitamin $\mathrm{C}$ led to a return to baseline measures [21]. In a similar fashion to the case series of dermatology patients described earlier, subjects in this study were replenished with varying levels of vitamin $C$, and the return to baseline measures of personality occurred even in those subjects with the lowest vitamin $C$ daily dose (6.5 mg daily) during the repletion phase.

Two cross-sectional studies quantified mood symptoms in subjects divided into lower and higher vitamin $\mathrm{C}$ plasma or serum concentrations. Both of these studies, in which subjects did not necessarily evince the physical manifestations of scurvy, provide further evidence of a link between low vitamin C status and depression. A 2018 study reported on a cohort of male students in Christchurch, New Zealand ( $\mathrm{n}=139$, aged 18 to 35 years) was divided into two groups based on their fasting plasma vitamin $C$ concentration: adequate $(\geq 50 \mu \mathrm{mol} / \mathrm{L}, \mathrm{n}=99)$ and inadequate $(<50 \mu \mathrm{mol} / \mathrm{L}, \mathrm{n}=40)$. The level for "inadequate" was considerably higher than the lower limit of the normal range endorsed by the Royal College of Pathologists of Australasia, which is about $30 \mu \mathrm{mol} / \mathrm{L}$. Using the Profile of Mood States (POMS) questionnaire, participants with inadequate vitamin $\mathrm{C}$ status had significantly higher POMS scores (i.e., greater disturbance) for total mood disturbance $(\mathrm{p}=0.024)$, depression $(\mathrm{p}=0.012)$ and confusion $(\mathrm{p}=0.022)$, compared to those with adequate vitamin $\mathrm{C}$ status [24]. In a cohort of 129 women in Italy in 1990, aged 60 to 90 years, depression was assessed using the depression section of the Inventory of Psychic and Somatic Complaints-Elderly. The cohort was divided into two groups, based on their serum ascorbic acid level - the low level group (serum ascorbic acid $<23 \mu \mathrm{mol} / \mathrm{L}, \mathrm{n}=27$ ) and high serum ascorbic acid group ( $\geq 23 \mu \mathrm{mol} / \mathrm{L}, \mathrm{n}=102)$. There was a statistically significantly higher mean depression score in the low serum ascorbic acid group compared to the high serum ascorbic acid group (1.96 \pm 0.66 vs. $1.57 \pm 0.56, \mathrm{p}<0.005)[25]$.

\section{Cognitive impairment}

In a case series published in 1971, a degree of confusion was noted in seven elderly women (age range, 70 to 95 years) with ascorbic acid deficiency. One woman also reported lethargy and depression. It is reported that one of these women recovered with a fortnight of ascorbic acid $1 \mathrm{~g}$ daily [26].

Two cross-sectional studies were identified which linked lower vitamin $\mathrm{C}$ status to greater cognitive impairment. In a 1996 cohort of elderly people living in Britain ( $\mathrm{n}=921$, ages 65 and over), cognitive function was assessed with the Hodkinson abbreviated mental test, with participants divided into groups based on score (those who scored the maximum of 10 were assessed as having no cognitive impairment; those scoring 9 or less were assessed as having some cognitive impairment). Plasma ascorbic acid status was stratified into three groups: normal $(>27.82 \mu \mathrm{mol} / \mathrm{L}, \mathrm{n}=274)$, mild deficiency (11.92 to $27.82 \mu \mathrm{mol} / \mathrm{L}, \mathrm{n}=302)$, and moderateto-severe deficiency ( $\leq 11.91 \mu \mathrm{mol} / \mathrm{L}, \quad \mathrm{n}=275)$. Moderate-to-severe, but not mild, ascorbic acid deficiency was associated with an increased risk of cognitive impairment. For those with mild deficiency, the unadjusted OR was 1.3 (95\% CI, 0.9 to 1.8), and for moderate-to-severe deficiency, the unadjusted OR was 1.9 (1.3 to 2.7). Odds ratio was also adjusted for vitamin $\mathrm{C}$ daily intake, social class, age (per decade) and stratified diastolic blood pressure. Adjusted OR for mild ascorbic acid deficiency was 1.1 (0.8 to 1.7), and for moderate-to-severe deficiency, 1.6 (1.1 to 2.3) [27]. In a 2017 cohort of people aged 49 to 51 years in Christchurch, New Zealand $(n=404)$, higher plasma vitamin C status correlated with lower levels of mild cognitive impairment, as assessed by the Montreal Cognitive Assessment test. The odds ratio (OR) for mild cognitive impairment for those with plasma vitamin $\mathrm{C}$ below $23 \mu \mathrm{mol} / \mathrm{L}$, compared to those with plasma vitamin C above this level, was 2.1 (95\% confidence interval [CI] 1.2, 3.7). Notably, in contrast to studies described earlier in this Results section, there was no association between plasma vitamin $C$ status and well-being or depression, as assessed by the Warwick-Edinburgh Mental Wellbeing Scale or the Mini-International Neuropsychiatric Interview [28]. In a 2019 cohort of healthy adults in Australia ( $\mathrm{n}=80$, ages 24 to 96 ), cognitive function was assessed by the Modified Mini Mental State Examination (3MS), the Revised Hopkins Verbal Learning Test (HVLT-R), the Symbol Digits Modalities Test (SDMT) and the Swinburne University Computerized Cognitive Assessment Battery (SUCCAB). Plasma vitamin C status was 
stratified into adequate $(\geq 28 \mu \mathrm{mol} / \mathrm{L}, \mathrm{n}=67)$ and deficient $(<28 \mu \mathrm{mol} / \mathrm{L}, \mathrm{n}=13)$. There was no difference between the adequate and deficient groups with respect to assessment of major cognitive impairment with 3MS. However, the adequate vitamin $\mathrm{C}$ group had statistically significantly higher scores on measures of recognition and immediate and delayed recall (assessed with HVLT$\mathrm{R}$ ) and on SDMT (assessing divided attention, tracking and visual screening) than the deficient group. Finally, using SUCCAB, the ratio of accuracy to reaction time was significantly higher in the adequate vitamin $C$ group for certain tasks (visual perception decision time, immediate and delayed non-verbal recognition memory, and, when adjusting for age, one of two measures of executive functioning and inhibition). There was no difference between the adequate and deficient groups with respect to measures of episodic memory or general alertness and motor speed [29].

\section{Discussion}

Unfortunately, as noted above, the studies in this review were often of relatively low methodological quality. In addition, those studies that included patients with scurvy were all case series. Furthermore, with the exception of a study that assessed the effects of induced vitamin $\mathrm{C}$ deficiency in a small group of healthy male prisoners, the relationship between vitamin $\mathrm{C}$ and neuropsychiatric outcomes in other studies was assessed cross-sectionally. Future research may include more robust study designs, such as case-control or cohort studies, to assess the effect of vitamin $\mathrm{C}$ deficiency on neuropsychiatric outcomes. Nonetheless, the overall trend from the studies included in this systematic review indicates that vitamin $\mathrm{C}$ deficiency is associated with an increase in depression $[21,24,25]$ and cognitive impairment [27-29]. Scurvy i.e., vitamin $\mathrm{C}$ deficiency with physical manifestations is also associated with depression [22, 23] and confusion [26]. Given the paucity of research in this area to date, one fruitful avenue for future research would be specifically investigating whether vitamin $\mathrm{C}$ deficiency is linked to other psychiatric diagnoses, including psychosis and anxiety.

It is noteworthy that so few relevant studies were identified as appropriate for inclusion in this systematic review. It may also be supposed that studies investigating the neuropsychiatric effects of scurvy have been scarce given widespread perceptions about the scurvy's rarity, incorrect as these assumptions may be. With respect to studies investigating vitamin $\mathrm{C}$ deficiency more broadly, there appears to be a sense that studies focusing on individual nutrients are outmoded. The Dietary Guidelines for Americans, for example, address diet in a holistic fashion, noting that "the eating pattern may be more predictive of overall health status and disease risk than individual foods or nutrients" [30]. It does not negate a the complexity of the interactions between food components and nutrients, or a holistic approach to nutrition, to point out that deficiencies of individual nutrients can, in and of themselves, produce significant clinical problems. In the field of psychiatry, one needs only to consider Wernicke-Korsakoff syndrome or pellagra as pertinent examples. This literature review highlights the importance of considering individual nutrients in psychiatric research, rather than solely focusing on diet in the broader sense. It is also noteworthy that only studies indicating the existence of a link between vitamin $\mathrm{C}$ deficiency and neuropsychiatric outcomes were identified in this review; this suggests that there may be systemic biases favouring in the publication of studies with positive results. Nonetheless, there are prima facie strong reasons for associating vitamin $\mathrm{C}$ deficiency with neuropsychiatric effects. In humans, neuroendocrine tissue such as the adrenal and pituitary glands have the highest concentration of ascorbic acid [31], with some studies indicating that the brain also has high ascorbic acid content relative to other organs [32]. In rats, the ascorbic acid content of cortical neurons is over ten times that of glia, consistent with neurons having a marked increase in oxidative metabolism and an increased susceptibility to oxidative stress [33]. In both humans and rats, ascorbate content is highest in the amygdala, hippocampus and hypothalamus relative to other brain areas. Rat studies also indicate higher levels of ascorbate in the neocortex and, to a relatively greater degree compared to other brain areas in humans, the nucleus accumbens $[34,35]$. These areas may be especially vulnerable to oxidative stress. In rats, hypothyroidism-induced oxidative stress, as assessed by lipid peroxidation, has been shown to affect the amygdala and hippocampus, but not the cerebellum, motor cortex or striatum [36]. There is also a physiological role of reactive oxygen species in vitamin C-rich brain regions, including the hippocampus, hypothalamus, amygdala and cerebral cortex, where they act as second messengers in mechanisms of synaptic plasticity, [37] which suggests that vitamin C plays a crucial role in maintaining homeostasis of reactive oxygen species. Ascorbic acid also has a role in modulating glutamatergic neurotransmission, [38] and the distribution of the glutamatergic NMDA receptors is highest in areas of high vitamin $C$ concentration, including areas of the cortex, the amygdala and the hippocampus [39].

It may be supposed that differential effects of vitamin C deficiency on areas of the limbic and cortical systems involved in cognition and mood regulation may explain the specific phenotype of depressive symptoms and cognitive impairment seen in vitamin $C$ deficiency. Behavioural phenotypes of vitamin $\mathrm{C}$ deficiency have been observed in animal models, providing further evidence for the clinical 
significance of vitamin $\mathrm{C}$ status on mood. L-gulono- $\gamma$-lactone oxidase, encoded by the GULO gene, is the ratelimiting enzyme in mammalian vitamin $C$ synthesis, and is non-functional in humans. GULO knockout mice fed a vitamin $\mathrm{C}$ deficient diet can therefore act as an animal model for scurvy. In one study, GULO knockout mice displayed lower activity levels and indicated a possible mild deficit in motor function [40]. Another study reported that GULO knockout mice had significantly lower brain levels of dopamine and serotonin metabolites. The gene knockout mice also displayed behavioural changes including lower levels of locomotor activity and altered social behaviour, possibly accounted for by depressive-like behaviour [41]. The lower activity levels observed in mice may be analogous to some mood symptoms seen in humans, including John Woodall's 1617 description of "generall lazinesse" [19].

In this present systematic review, the included studies in this review employed a number of different measurement techniques for vitamin $\mathrm{C}$, including blood levels, leucocyte levels and a vitamin $\mathrm{C}$ saturation test. For the included case series of clinical vitamin $\mathrm{C}$ deficiency, two older studies published in 1968 and 1971 primarily utilised leucocyte ascorbic acid level [22, 26]. Walker [22] measured vitamin $C$ in milligram per $100 \mathrm{mg}$ of white blood cells, while Mitra [26] measured vitamin $C$ in milligram per $100 \mathrm{~g}$ of white blood cells. (The former study likely reported incorrect measurements; vitamin C in leucocyte layer is typically reported in milligram per $100 \mathrm{~g}$ of white blood cells [42].) As previously noted, leucocyte ascorbic acid, whilst a more difficult assessment to undertake than plasma ascorbate, is a better indicator of vitamin $\mathrm{C}$ tissue and body stores. The study by Walker [22] also included a vitamin $\mathrm{C}$ saturation test, whereby subjects were administered $700 \mathrm{mg}$ of vitamin $\mathrm{C}$ daily, and 24-h urine specimens were assessed for estimation of total vitamin $C$ content. An excretion of $\geq 70 \%$ of the $700 \mathrm{mg}$, on the second day of testing, was considered to be normal. It has been suggested that such tests may be beneficial in the clinical diagnosis of scurvy [1].

In addition, the definition of vitamin $C$ deficiency varied between studies. Three included studies [22, 23, 26] investigated patients with a diagnosis of scurvy. Of the other included studies, only one study included a definition of vitamin $\mathrm{C}$ deficiency which was comparable to that which is associated with clinical manifestations of scurvy; in this study, moderate-to-severe deficiency was defined as $\leq 11.91 \mu \mathrm{mol} / \mathrm{L}$ [27]. The cut-off definition of vitamin $\mathrm{C}$ deficiency in most other studies was comparable to the lower end of the normal laboratory reference range, although one study [24] defined "inadequate" vitamin C levels as less than $50 \mu \mathrm{mol} / \mathrm{L}$; it was not clear how this was determined to represent inadequate levels. While there are disparate definitions of vitamin C deficiency in patients without scurvy, the included studies indicate that psychiatric sequelae of vitamin $\mathrm{C}$ deficiency may occur at levels higher than those associated with clinical manifestations of scurvy.

From a clinical perspective, the degradation of ascorbic acid with heat and light leads to problems both in dietary intake and in measuring blood or plasma levels. With respect to dietary intake, levels of ascorbic acid do not stay constant in fruits and vegetables, and vary depending on the method of storage. For example, when stored at ambient temperatures, fresh spinach has been shown to lose all of its ascorbic acid content within 4 days, and green peas lost approximately half of the ascorbic acid content within the first 2 days after harvest [43]. It is therefore possible that many psychiatric patients would have inadequate vitamin $\mathrm{C}$ intake even if fruit and vegetables are included in their diets, as the fruit and vegetables may not be fresh.

In addition, testing patients for ascorbic acid levels is difficult, due to the precautions needed with handling blood samples - the samples must be placed on ice immediately, and protected from light. Whilst both difficulties in laboratory testing and the ease and inexpensiveness of vitamin $C$ replacement may suggest that vitamin $C$ supplementation globally in psychiatric patients is warranted, there is still a risk of over-replacement causing morbidity. For example, the relationship between neonatal vitamin D status and schizophrenia is a U-shaped curve - while low vitamin D status in neonates is associated with an increased risk of schizophrenia, so is a high vitamin D status [44]. Consequently, it may be prudent to judiciously limit vitamin $C$ replacement to those patients with low vitamin $\mathrm{C}$ levels or with clinical signs of scurvy, rather than broadly to all mental health patients.

\section{Conclusion}

The findings of this systematic review, in addition to the epidemiology of vitamin $\mathrm{C}$ deficiency, indicate that vitamin $C$ status should be appropriately assessed in certain psychiatric patient groups, such as patients presenting with symptoms which could be related to vitamin $\mathrm{C}$ deficiency (for example, depression, confusion or cognitive impairment) or high-risk patient groups, including those with poor dietary intake. Crucially, mental health clinicians must be alert to the physical signs of scurvy, and the clinical manifestations of this disease on physical examination, such as gingival bleeding, bruising, petechiae and perifollicular haemorrhage [2]. Furthermore, consultation-liaison psychiatrists, and non-psychiatric medical professionals, must be alert to the psychiatric adverse effects of vitamin $\mathrm{C}$ deficiency. As has been noted previously, the occurrence of symptomatic vitamin $\mathrm{C}$ deficiency represents "an evidence practice gap of more than 250 years" [15]. 


\section{Abbreviations}

OR: Odds ratio; 3MS: Modified Mini Mental State Examination; HVLT-R: The Revised Hopkins Verbal Learning Test; SDMT: The Symbol Digits Modalities Test; SUCCAB: The Swinburne University Computerized Cognitive Assessment Battery

\section{Acknowledgements}

The authors wish to acknowledge the assistance of Ms. Maureen Bell in the preparation of the literature search strategy.

\section{Authors' contributions}

DP and CG contributed equally to writing the manuscript. DP reviewed titles and abstracts of all articles and completed data extraction; CG independently verified the review and data extraction. All authors read and approved the final manuscript.

\section{Funding}

The authors declare that this research received no specific funding from any agency in the public or private sectors.

\section{Availability of data and materials}

Data sharing is not applicable to this article as no datasets were generated or analysed during the current study.

\section{Ethics approval and consent to participate} Not applicable.

\section{Consent for publication}

Not applicable.

\section{Competing interests}

The authors declare that they have no competing interests.

\section{Author details}

${ }^{1}$ Central Adelaide Local Health Network, Adelaide, SA, Australia. ${ }^{2}$ Discipline of Psychiatry, The University of Adelaide, Adelaide, SA, Australia. ${ }^{3}$ Ramsay Health Care Mental Health, Gilberton, SA, Australia. ${ }^{4}$ Northern Adelaide Local Health Network, Adelaide, SA, Australia.

\section{Received: 9 September 2019 Accepted: 12 June 2020}

\section{Published online: 18 June 2020}

\section{References}

1. Rifai N, Horvath AR, Wittwer C. Tietz textbook of clinical chemistry and molecular diagnostics. 6th ed. St. Louis: Elsevier; 2018.

2. Russell RM, Suter PM. Vitamin and trace mineral deficiency and excess. In: Kasper DL, Fauci AS, Hauser SL, Longo DL, Jameson JL, Loscalzo J, editors. Harrison's principles of internal medicine. 19th ed. New York: McGraw-Hill Education; 2015

3. Camarena V, Wang G. The epigenetic role of vitamin $C$ in health and disease. Cell Mol Life Sci. 2016;73(8):1645-58.

4. Padayatty SJ, Levine M. Vitamin C: the known and the unknown and goldilocks. Oral Dis. 2016;22(6):463-93.

5. Harrison FE, May JM. Vitamin C function in the brain: vital role of the ascorbate transporter SVCT2. Free Radic Biol Med. 2009:46(6):719-30.

6. Moretti M, Fraga DB, Rodrigues ALS. Ascorbic acid to manage psychiatric disorders. CNS Drugs. 2017;31(7):571-83.

7. Baker EM, Hodges RE, Hood J, Sauberlich HE, March SC, Canham JE. Metabolism of 14C- and 3H-labeled L-ascorbic acid in human scurvy. Am J Clin Nutr. 1971;24(4):444-54.

8. Chazan JA, Mistilis SP. The pathophysiology of scurvy. A report of seven cases. Am J Med. 1963;34(3):350-8.

9. Levine M, Conry-Cantilena C, Wang Y, Welch RW, Washko PW, Dhariwal KR et al. Vitamin C pharmacokinetics in healthy volunteers: evidence for a recommended dietary allowance. Proc Natl Acad Sci U S A. 1996;93(8): 3704-9.

10. Washko PW, Welch RW, Dhariwal KR, Wang Y, Levine M. Ascorbic acid and dehydroascorbic acid analyses in biological samples. Anal Biochem. 1992; 204(1):1-14

11. RCPA manual. Royal College of Pathologists of Australasia manual. 7th ed Surry Hills: Royal College of Pathologists of Australasia; 2015.
12. Newton HMV, Morgan DB, Schorah CJ, Hullin RP. Relation between intake and plasma concentration of vitamin C in elderly women. Br Med J. 1983; 287(6403): 1429.

13. Schleicher RL, Carroll MD, Ford ES, Lacher DA. Serum vitamin C and the prevalence of vitamin C deficiency in the United States: 2003-2004 National Health and nutrition examination survey (NHANES). Am J Clin Nutr. 2009; 90(5):1252-63.

14. Mosdøl A, Erens B, Brunner EJ. Estimated prevalence and predictors of vitamin C deficiency within UK's low-income population. J Public Health. 2008;30(4):456-60

15. Gabb G, Gabb B. Scurvy not rare. Aust Fam Physician. 2015;44(7):438-40.

16. Christie-David DJ, Gunton JE. Vitamin C deficiency and diabetes mellitus easily missed? Diabet Med. 2017;34(2):294-6.

17. Dipasquale S, Pariante CM, Dazzan P, Aguglia E, McGuire P, Mondelli V. The dietary pattern of patients with schizophrenia: a systematic review. J Psychiatr Res. 2013;47(2):197-207.

18. Lind J. A treatise of the scurvy. In three parts. Containing an inquiry into the nature, causes and cure, of that disease. Together with a critical and chronological view of what has been published on the subject. A Millar: Edinburgh; 1753.

19. Woodall J. The surgions mate, or, a treatise discouering faithfully and plainely the due contents of the surgions chest. London: L Lisle; 1617.

20. Young DS. Implementation of SI units for clinical laboratory data. Style specifications and conversion tables. Ann Intern Med. 1987;106(1):114-29.

21. Kinsman RA, Hood J. Some behavioral effects of ascorbic acid deficiency. Am J Clin Nutr. 1971:24(4):455-64.

22. Walker A. Chronic scurvy. Br J Dermatol. 1968;80(10):625-30.

23. Deligny C, Dehlinger V, Goëb V, Baptiste GJ, Arfi S. Paradoxical appearance of adult scurvy in Martinique, French West Indies. Eur J Intern Med. 2011; 22(2):e7-8.

24. Pullar JM, Carr AC, Bozonet SM, Vissers MCM. High vitamin C status is associated with elevated mood in male tertiary students. Antioxidants. 2018; 7(7), art. no. 91.

25. Marazzi MC, Mancinelli S, Paolmbi L, Martinoli L. D'Alessandro de Luca E, Buonomo $E$, et al. Vitamin $C$ and nutritional status of institutionalized and noninstitutionalized elderly women in Rome. Int J Vitam Nutr Res. 1990; 60(4):351-9.

26. Mitra ML. Confusional states in relation to vitamin deficiencies in the elderly J Am Geriatr Soc. 1971;19(6):536-45.

27. Gale CR, Martyn CN, Cooper C. Cognitive impairment and mortality in a cohort of elderly people. Br Med J. 1996;312(7031):607-11.

28. Pearson JF, Pullar JM, Wilson R, Spittlehouse JK, Vissers MCM, Skidmore PML, et al. Vitamin C status correlates with markers of metabolic and cognitive health in 50-year-olds: Findings of the CHALICE cohort study. Nutrients. 2017:9(8), art. no. 831

29. Travica N, Ried K, Sali A, Hudson I, Scholey A, Pipingas A. Plasma Vitamin C concentrations and cognitive function: A cross-sectional study. Front Aging Neurosci. 2019;11(APR), art. no. 072

30. U.S. Department of Health and Human Services and U.S. Department of Agriculture. 2015-2020 Dietary Guidelines for Americans. 8th ed; 2015

31. Hornig D. Distribution of ascorbic acid, metabolites and analogues in man and animals. Annals of the New York Academy of Sciences; 1975. p. 103-18.

32. Yavorsky $M$, Almaden $P$, King CG. The vitamin $C$ content of human tissues. J Biol Chem. 1934;106:525-9.

33. Rice ME, Russo-Menna I. Differential compartmentalization of brain ascorbate and glutathione between neurons and glia. Neuroscience. 1997 82(4):1213-23.

34. Milby K, Oke A, Adams RN. Detailed mapping of ascorbate distribution in rat brain. Neurosci Lett. 1982;28(1):15-20.

35. Mefford IN, Oke AF, Adams RN. Regional distribution of ascorbate in human brain. Brain Res. 1981;212(1):223-6.

36. Cano-Europa E, Pérez-Severiano F, Vergara P, Ortiz-Butrón R, Ríos $C$, Segovia J, et al. Hypothyroidism induces selective oxidative stress in amygdala and hippocampus of rat. Metab Brain Dis. 2008:23(3):275-87.

37. Beckhauser TF, Francis-Oliveira J, De Pasquale R. Reactive oxygen species: physiological and physiopathological effects on synaptic plasticity. J Exp Neurosci. 2016;2016:23-48

38. Travica N, Ried K, Sali A, Scholey A, Hudson I, Pipingas A. Vitamin c status and cognitive function: a systematic review. Nutrients. 2017;9(9):1-21.

39. Kornhuber J, Mack-Burkhardt F, Riederer P. Regional distribution of [3H]MK801 binding sites in the human brain. Brain Res. 1989;489(2):397-9. 
40. Chen Y, Curran CP, Nebert DW, Patel KV, Williams MT, Vorhees CV. Effect of vitamin $\mathrm{C}$ deficiency during postnatal development on adult behavior: functional phenotype of Gulo(-/-) knockout mice. Genes Brain Behav. 2012; 11(3):269-77.

41. Harrison FE. Behavioural and neurochemical effects of scurvy in gulo knockout mice. J Marit Res. 2013;15(1):107-14.

42. Butler AM, Cushman M. Distribution of ascorbic acid in the blood and its nutritional significance. J Clin Investig. 1940;19(3):459-67.

43. Rickman JC, Barrett DM, Bruhn CM. Nutritional comparison of fresh, frozen and canned fruits and vegetables. Part 1. Vitamins $C$ and $B$ and phenolic compounds. J Sci Food Agric. 2007;87(6):930-44.

44. McGrath JJ, Eyles DW, Pedersen CB, et al. Neonatal vitamin D status and risk of schizophrenia: a population-based case-control study. Arch Gen Psychiatry. 2010;67(9):889-94.

\section{Publisher's Note}

Springer Nature remains neutral with regard to jurisdictional claims in published maps and institutional affiliations.

- fast, convenient online submission

- thorough peer review by experienced researchers in your field

- rapid publication on acceptance

- support for research data, including large and complex data types

- gold Open Access which fosters wider collaboration and increased citations

- maximum visibility for your research: over $100 \mathrm{M}$ website views per year

At $\mathrm{BMC}$, research is always in progress. 